\title{
Comment to "The effects of Kinesio taping of lower limbs on functional mobility, spasticity, and range of motion of children with spastic cerebral palsy" by Mirjavad Tabatabaee et al.
}

\author{
Faizan Zaffar Kashoo ${ }^{1 *}$ (i) and Mehrunnisha Ahmad²
}

Keywords: Letter to editor, Cerebral palsy, Kinesio taping

Dear Editor,

\section{Introduction}

We read the article with interest titled "The effects of Kinesio taping of lower limbs on functional mobility, spasticity, and range of motion of children with spastic cerebral palsy" published in The Egyptian Journal of Neurology, Psychiatry and Neurosurgery on 29th October (2019) 55:70 [1]. We want to commend the authors for this useful clinical study and a significant contribution towards the body of scientific knowledge related to evidence-based cerebral palsy $(\mathrm{CP})$ rehabilitation. The study evaluates the effect of Kinesio taping (KT) in children with spastic CP. The study population comprises diplegic and quadriplegic $\mathrm{CP}$ children equally allocated into two groups. Group A received conventional therapy plus sham KT, whereas Group B received conventional plus real KT. The study uses goniometric measurements for the joint range of motion, Modified Ashworth Scale for spasticity, and Timed Up and Go Test for functional mobility of the lower limbs. Although the introduction, research design, and statistical analysis are plausible,

\footnotetext{
* Correspondence: f.kashoo@mu.edu.sa

'Department of Physical Therapy and Health Rehabilitation, College of Applied Medical Sciences, Majmaah University, Majmaah, Province Riyadh 11952, Kingdom of Saudi Arabia

Full list of author information is available at the end of the article
}

there are few methodological concerns in the article which need to be addressed by the authors.

\section{Main text}

First, the authors did not perform a power analysis to determine the optimal sample size compromising the internal validity of the study. Second, the KT was applied for $24 \mathrm{~h}$ and continued for 4 days, such prolonged use can deteriorate the adhesive property of $\mathrm{KT}$ with time or if it comes in contact with water during hygienic activities. Third, an electromyography study revealed the positive facilitatory effects of KT when applied over quadriceps muscle for $24 \mathrm{~h}$ [2]. However, the inhibitory effect of KT on muscle when applied without tension lacks scientific evidence. Fourth, the study used Timed Up and Go test to evaluate functional mobility. Test usage is limited due to a lack of validation studies in the $\mathrm{CP}$ population. However, validated and reliable functional evaluation tools are available for children with $\mathrm{CP}$ such as the Functional Mobility Scale [3] and expanded and revised Gross Motor Function Classification System [4]. Fifth, the authors conclude that there is no significant difference between the control and experimental group. Both the groups received KT; the experimental group received $\mathrm{KT}$ with proper technique, whereas the control group received KT with sham technique. Therefore, both groups would receive the beneficial effect of tactile stimulation due to the application of KT over the 
skin [5]. The tactile stimulation by KT, when applied over the dermatome of the affected muscle group, would result in facilitation to the corresponding myotome through a monosynaptic spinal reflex [6].

\section{Conclusion}

The study adds an important complementary therapy that would augment the effect of interventions in CP rehabilitation. The study opens the door to investigate the facilitatory and inhibitory effects of KT by electromyographic studies.

\section{Abbreviations}

KT: Kinesio taping; CP: Cerebral palsy

\section{Acknowledgements}

Not applicable

\section{Authors' contributions}

FZK conceived the idea and drafted the manuscript. MA assisted with developing the manuscript by adding supporting articles with respect to the intellectual content. Both authors read and approved the final manuscript.

\section{Funding}

None

\section{Availability of data and materials}

Data sharing is not applicable to this article as no datasets were generated or analyzed during the current study.

\section{Ethics approval and consent to participate}

Not applicable

\section{Consent for publication}

All authors consent for publication

\section{Competing interests}

The authors declare that they have no competing interests.

\section{Author details}

'Department of Physical Therapy and Health Rehabilitation, College of Applied Medical Sciences, Majmaah University, Majmaah, Province Riyadh 11952, Kingdom of Saudi Arabia. ²Department of Nursing, College of Applied Medical Sciences, Majmaah University, Majmaah 11952, Kingdom of Saudi Arabia.

Received: 29 November 2019 Accepted: 10 March 2020

Published online: 23 March 2020

\section{References}

1. Tabatabaee M, Cheraghifard M, Shamsoddini A. The effects of kinesio taping of lower limbs on functional mobility, spasticity, and range of motion of children with spastic cerebral palsy. Egypt J Neurol Psychiatry Neurosurg. 2019;55(1):70.

2. Słupik A, Dwornik M, Białoszewski D, Zych E. Effect of Kinesio Taping on bioelectrical activity of vastus medialis muscle. Preliminary report. Ortop Traumatol Rehabil. 2007;9(6):644-51.

3. Adair B, Said CM, Rodda J, Morris ME. Psychometric properties of functional mobility tools in hereditary spastic paraplegia and other childhood neurological conditions. Dev Med Child Neurol. 2012;54(7):596-605.

4. Palisano RJ, Rosenbaum P, Bartlett D, Livingston MH. Content validity of the expanded and revised Gross Motor Function Classification System. Dev Med Child Neurol. 2008:50(10):744-50.

5. Konishi Y. Tactile stimulation with Kinesiology tape alleviates muscle weakness attributable to attenuation of la afferents. J Sci Med Sport. 2013; 16(1):45-8.
6. Bagheri R, Pourahmadi MR, Sarmadi AR, Takamjani IE, Torkaman G, Fazeli SH. What is the effect and mechanism of kinesiology tape on muscle activity? J Bodyw Mov Ther. 2018;22(2):266-75.

\section{Publisher's Note}

Springer Nature remains neutral with regard to jurisdictional claims in published maps and institutional affiliations.

\section{Submit your manuscript to a SpringerOpen ${ }^{\circ}$ journal and benefit from:}

- Convenient online submission

- Rigorous peer review

- Open access: articles freely available online

- High visibility within the field

- Retaining the copyright to your article

Submit your next manuscript at $\boldsymbol{\nabla}$ springeropen.com 